\title{
Pythagorean Cosmology in The Dead
}

\author{
Shenghua Yang ${ }^{1}$ \\ ${ }^{1}$ School of Foreign Languages, China West Normal University, Nanchong, China \\ Correspondence: Shenghua Yang, School of Foreign Languages, China West Normal University, Nanchong, \\ Sichuan, China. Tel: 86-151-8178-9712. E-mail: yangshenghua2014@sina.com
}

Received: January 1, 2015 Accepted: January 25, 2015 Online Published: February 25, 2015

doi:10.5539/ells.v5n1p86 URL: http://dx.doi.org/10.5539/ells.v5n1p86

\begin{abstract}
James Joyce is one the most influential writers in the 20th century. The Dead is the last, the synthesis and climax of Joyce's Dubliners. Critics have made researches in detail on the artistic features and the theme of The Dead from different points of view such as historicism, colonialism, psychoanalytical criticism, feminist criticism and narratology. Very few critics have noticed the influence of Pythagorean Cosmology in Joyce's works, though it is prevailing in The Dead. This article analyses The Dead written by James Joyce from new perspectives of music and space based upon Pythagorean Cosmology, and explores the peculiar and rich content of music and space in Joyce's works. The finding of the application of music and space in The Dead will be helpful to highlight the aspects which we may have overlooked and add a new dimension to interpret The Dead.
\end{abstract}

Keywords: The Dead, Pythagorean Cosmology, music, space

\section{Introduction}

"James Joyce is considered as one of the most influential writers of the 20th century. Many critics judge that he is second only to Shakespeare in his mastery of English language."(Booze, 1984, p. 30) He revolutionizes the methods of depicting and develops a special way of constructing a novel. His books provide penetrating insights into human nature. The research on The Dead is an indispensable part of the study on his Dubliners. With the development of modernism in literature, the artistic quality and aesthetic value of Dubliners are accepted by more and more critics. Some critics hold the view that Dubliners is rather a work that realistically reflects the common people's life in Dublin and it is greatly affected by modernism and naturalism although Joyce is one of the important representatives who uses the technique of "stream of consciousness". The Dead is the last story in Dubliners and the synthesis and climax of Dubliners as well. The Dead is a story about man's withdrawal into the circle of his own egotism and the subsequent breakdown between man and his world due to external assaults on his egotism and greater internal understanding of the world around him. Critics have made researches in detail on the artistic features and the theme of The Dead from different points of view such as historicism, colonialism, psychoanalytical criticism, feminist criticism and narratology.

As for artistic features of The Dead, Joyce is noted for his experimented language. Some critics have discussed the story from the angle of its language. As for creative techniques, some papers mainly concentrate on his writing technique such as "stream of consciousness" and the use of figures of speech like comparison and satire. Other papers focus the attention on symbolism and epiphany, such as the symbolic meaning of "snow" and Gabriel's "epiphany". The themes of The Dead are colorful due to the current criticism. Apart from the spiritual paralysis, other themes such as death, rebirth, love and hatred, death in life and life in death are the most accepted views. Furthermore, some critics make a comparison between The Dead and other works to find out the similarities between them and probe into the relationship between Joyce and The Dead. Moreover, post-colonialism emphasizes the Irish nationality from the perspective of geographical scale and genealogy, reveals Joyce's attitude towards the issue, and concludes that he is a political-oriented writer. It is noted that few studies of The Dead have been made from the perspective of Pythagorean Cosmology, especially the perspective of music and space. This article seeks to highlight Joyce's application of music and space in The Dead and aims to fill up the vacancy of narratology embodied in The Dead according to Pythagorean Cosmology so as to know how music and space play pivotal roles in The Dead. 


\section{Discussion}

\subsection{Pythagorean Cosmology}

Pythagoras was the most eminent of all the ancient Philosophers. Indeed, the sect of Pythagoras, exerting great influence upon the two best known schools, the Academy of Plato and the Lyceum of Aristotle, has played a definite and important role in the development of Western philosophy.

According to Pythagorean cosmology, "Cosmology means the composition of the universe, how our world is put together. It comprises our beliefs about the fundamental constituents of the environment. So actually, cosmology is an analysis of ultimate reality. Many different things have at one time or another been urged as the elemental components of reality. A few of the better known include atoms(both in classical times and in our own), the sense data of humans, the mental impressions of humans, bundles of energy, electronic fields, ideas in the Platonic sense, numbers as defined by the Pythagoreans, and basic qualities (such as hot, cold, moist, and dry). Cosmology consists in designating the intrinsic ingredients of reality and defining the interrelations between them." (Heninger, 1974, p. 6) In this sense, the cosmos is dominated by a well-ordered, harmonious circular movement. It is also a kind of perfect and limited space, which is arranged in an ordered hierarchy, ranging from the lowest to the highest. The earth rests at the center of it. Cosmology emphasizes the relationship between cosmos and man, the interactions of all levels. The chain of being is an attempt to deal with metaphysical problem. The physical realm is comprised of (in ascending order) stones, plants, and animals, and the conceptual realm is comprised of (in descending order) God and the angels. And man is the nexus between them, holding the physical and the conceptual together in a single entity and providing a means of intercourse between them. Man is literally the crucial link between them. It is noted that the core of this cosmology consists in treating this universe as an infinite and self-maintaining construction. Our earth is placed at the centre of the universe and is surrounded by a series of spheres consisted of the planets and stars. The earth and the concentric spheres are set into a harmonious motion primum mobile or "first mover". This cosmology holds that the orderly and hierarchical arrangement out of chaos results from some cosmic forces, such as love and divine will. The cosmic forces are revealed clearly by music and space in The Dead.

\subsection{Music in The Dead}

In Pythagorean Cosmology, "the discipline of music, which by definition depends upon relationships between whole numbers, provides a natural expression of cosmos. Music provides a convenient way of relating the finite to the infinite, or better yet, of knowing the infinite through the finite." (Heninger, 1974, p. 156) In this sense, music plays pivotal role of relating God to man, relating knowledge and philosophy to man, and relating virtue to man. As Irish is talented in music, music is a distinguishing feature in literary works and many literary writers are also masters of music. James Joyce is not the exception. Music is the highlight and also the reflection of life in The Dead. Music can be divided into indoor music and outdoor music. Indoor music, which is the product of human civilization, is related to rational recognition. Outdoor music, as the sound of nature, reveals the power of cosmic life. Based on a great many musical materials including indoor music and outdoor music, The Dead reflects the Pythagorean Cosmology from a new point and has its profound meanings and vivid metaphors in music.

"Arrayed for the Bridal" is a kind of indoor music. Two aunts were very old and never enjoyed love and marriage. They were approaching death. Particularly, Aunt Julia always conformed to traditions and rules, and lacked vigor, although she was modest and hospitable. She sang "Arrayed for the Bridal" in the party every year. She was old and close to death, who was a sharp contrast to the young bride in the song. The song was full of vigor, sweetness and love, while Aunt Julia lived in the darkness and desolate house, never experiencing sweetness and love. Maybe, many years ago, when she was young she once made up herself to array the bridal. However, she was so old and gaunt now that her nephew Gabriel had the feeling that he would attend her funeral in the near future. Aunt Julia had waited for her wedding throughout her lifetime but no wedding appeared. The song "Arrayed for the Bridal" correlates the novel closely, forms a contrast to Aunt Julia's fate, lays the foundation for reads' understanding of the metaphor, irony and implication.

People discussed about the opera "Let Me Like a Soldier Fall" in the party, which implied the theme of death and the sharp contrast between the soldier in the opera and Gabriel. Gabriel lacked the air and spirit of soldier all the time. In the beginning of the story, he suffered a setback when he made a joke with Lily. He colored without looking at her as if he felt he had made a mistake. Gabriel colored again when he met Miss Ivors. "He glanced right and left nervously and tried to keep his good humor under the ordeal which was making a blush invade his forehead." (Joyce, 1996, p. 216) When he made a speech, "Gabriel leaned his ten trembling fingers on the tablecloth and smiled nervously at the company."(Joyce, 1996, p. 230) When Gretta talked about Fury, "it hardly 
pained him now to think how poor a part he, her husband, had played in her life."(James Joyce, 1996, p. 254) Fury was a true soldier, who pursued his love with folk song and passionate life. Gabriel envied Fury's death, his love and his spirit. The song "Let Me Like a Soldier Fall" plays pivotal role in character molding, plot linking and story narrating.

In "Mignon", Mignon loved Wilhelm Meister, but Wilhelm Meister loved Philine. In The Dead, Gabriel cared much for Gretta, but Gratta cared for Fury. In this sense, the two stories are narrated in the same way. Gabriel recalled the good memories of the past due to the grace of Gretta at the moment of listening "Distant Music". A sudden tide of joy went leaping out of his heart. "Gabriel's eyes were still bright with happiness. The blood went bounding along his veins; and the thoughts went rioting through his brain, proud, joyful, tender, valorous. Moments of their secret life together burst like stars upon his memory."(Joyce, 1996, p. 243) The tender feeling not only belonged to Gabriel, but also belonged to Gretta. "Distant Music" had the magical power that drew Gretta's attention to Fury's song and aroused her sweet and grieved memory of the past. Thus it was easy for her to have the spontaneous feeling. Her love belonged to the past, to Fury, although Gabriel loved her.

In "Lucrezia Borgia", duchess, Lucrezia Borgia recognized her bastard Gennaro and expressed her special care for him stemming from the nature of mother. Not knowing the fact, the duke attempted to kill Gennaro who was considered as a rival in love. Gennaro drank the poisonous wine and died in the bosom of his mother. Lucrezia also died of poison. Gabriel, sharing the similarity with the duke, satirized his wife and suspected that Gretta had a lover. Fury would rather shiver to death in the heavy rain than return home. The death of Gennaro implied the death of Fury and anticipated the theme of death. More importantly, the death of Lucrezia also offered a hint for the death of Gretta's passion. Gretta and Gabriel had hidden different intentions behind the semblance of accord for many years. The result of Lucrezia enriched the image of Gretta whose heart was elsewhere not here.

When all the quests sang a song together, a kind of harmony was reached in the party. It was the force of nature from the outdoor that touched some decayed circumstance indoor. The most striking outdoor music came from "The Lass of Aughrim". "The Lass of Aughrim" is an Irish folk song, which is an important clue of epiphany. In a noisy party, Gabriel noticed that "his wife was leaning on the banisters, listening to something. There was grace and mystery in her attitude as if she were a symbol of something. If he were a painter he would paint her in that attitude. Distant music he would call the picture if he were a painter."(Joyce, 1996, p. 240) The heart of Gabriel was brimming over with happiness. He slipped one arm swiftly about her body after returning the hotel and asked her what she was thinking about. Surprisingly, she told him that she was thinking about a young boy, Michael Furey, who used to sing that song for her. When Gretta was going to leave her grandmother's and came up here to the convent, Fury saw her off under a heavy rain. "There was the poor fellow at the end of the garden, shivering. I implored of him to go home at once and told him he would get his death in the rain. But he said he did not want to live. I can see his eyes as well as well."(Joyce, 1996, p. 253) When Gretta was only a week in the convent, Fury died and was buried in Oughterard. Although Fury was dead, he was still alive in Gretta's deep heart. The "Distant music" drew her attention easily and made her recall her unforgettable memories of the past, of Fury, of her first love. The song narrates that a young girl, who was seduced and abandoned by Lord, held the baby in her arms and sang this folk song outside the window of Lord's house. Similarly, Fury sang a song in the heavy rain. This scene anticipates Fury's death and Gretta's helplessness, widens the theme of novel, and makes the image of Fury vivid and impressive. In this sense, the cosmic forces, such as love and divine will are unveiled in the outdoor music- - "The Lass of Aughrim".

\subsection{Space in The Dead}

Space is an essential element in Cosmology. Space, as the most fundamental notion for ordering all modes of thoughts and beliefs, acts in fact in redefining history and existence in the modern world. And it results in a broad debate to make sense of the nature of space and its existence. Traditionally, space is divided into three levels in terms of original understanding: space of god, space of nature and space of man. "Dubliners makes space lose its traditional and natural meaning, mirrors social background of Dubline, the capital of Ireland, and reflects the emptiness of spirit and the waste land of deep feeling." (Crang \& Thrift, 2000, p. 30) The city, streets, natural scenes, social space and psychological space are essential parts of James Joyce's novels and important means to reveal modern spirit in the west. In The Dead, James Joyce describes space of nature, space of society and space of individual from different perspectives and mixes characters, nature and thoughts into space. The centre of paralysis is revealed successfully by means of space.

Landscape, which appears as region, scene and architecture, is an essential element in a novel. It is, to some extent, a metaphor. James Joyce uses skillfully all kinds of landscapes in Dublin and enables it to be special materials in bringing to light the profound theme in order to reveal "paralysis" in modern society. Landscape 
becomes a symbolic system from the perspective of space and also a kind of cultural interpretation based upon refined region. Snow, as the landscape of nature, is one of the typical symbols. There are so many descriptions of snow in the novel that we can see that the whole story narration is around the snow. For one thing, snow symbolizes the materials to nurture life. For another, it stands for the cold that has the power to frozen all the feelings, spirits and bodies. In particular, in the end of the novel, it seems that the snow has become the daemon of fate, crosses plain and marsh, hill and highland and falls upon all the living and the dead. The heavy snow in the end of the novel, showing the waste land of spirit, is regarded as a symbolic system and used as important means to express Joyce's theme:

Snow was general all over Ireland. It was falling on every part of the dark central plain, on the treeless hills, falling softly upon the Bog of Allen and, further westward, softly falling into the dark mutinous Shannon waves. It was falling, too, upon every part of the lonely churchyard on the hills where Michael Fury lay buried. It lay thickly drifted on the crooked crosses and headstones, on the spears of the little gate, on the barren thorns. His soul swooned slowly as he heard the snow falling faintly through the universe and faintly falling, like the descent of their last end, upon all the living and the dead. (Joyce, 1996, pp. 255-256)

The heavy snow is the focus of many critics. "It covers the past, the present and the future of Ireland."(Morris, 1973, p. 78) The heavy snow, graveyard, characters and plot constitute the complete system of special symbol. They symbolize the death of personal relationship, Irish society and spirit. The shadow of death is at every corner of Dublin. The name of the protagonist, Gabriel, refers to the angle who controls life, death and rebirth in Christianity. The angle of life talked with the depressed persons about death and cheating on Christmas day. The Dead expresses oppression, desolation and dullness. The whole society is a pond of dead water and lacks vigor of life. The heavy snow is a typically spatial metaphor and a negative force, reflecting paralysis in Irish spiritual life.

Space of society means not only the place where people live, but also the manners and results of their activities in social communication. It is the source and mirror of society. Therefore, space of society is the fight of two different thoughts, the oppression and rebellion between two classes. Meanwhile, it offers breadth and depth of plot development in the novel. In The Dead, Gabriel was a lecturer and free-lancer for literature magazine. His space of society is narrow and limited. A special shift appears in the beginning of the novel. Gabriel's space changes from his daily life, his work to his aunt's house. The heavy snow fell at that night and Gabriel attended the party with goloshes on his feet. James Joyce focuses on the goloshes. Gabriel walked into the narrow space of house from the broad space of the outside world. Ladies were communicating about the galoshes. Gretta told others that the goloshes on her feet were from the continent. At that time, few people in Ireland wore the goloshes coming from the continent, a broader space. The galoshes represented something civilized and advanced. Gabriel's aunt hated everything including galoshes in the continent and aunt Julia even did not know what the galoshes were. As for the heavy snow, the main characters in the novel held different ideas from Gabriel's. Gabriel hated and even avoided heavy snow. Not like Gabriel, they liked it. Aunt Julia expressed her affection towards snow. Different attitudes towards snow and galoshes are the reflection of the fight of two social spaces, of native and outside world. When Miss Ivors met Gabriel again in the party, they talked about happenings in college and Gabriel's review of Browning's poetry. Suddenly, she changed the topic and invited Gabriel to the Aran Isles. Gabriel refused her invitation with politeness and explained the reason that he would go to France or Belgium or perhaps Germany. Miss Ivors was puzzled that Gabriel would rather go to the continent rather than go to his own land to be familiar with his own language-Irish. She criticized that he knew nothing of his own country and his own people. Facing her criticism, Gabriel lost his air of gentleman and retorted suddenly that he was sick of his own country. Their thoughts conflicted violently in the space of society.

Space of individual is a representative space that is gifted with individual features. It refers to the place with typical features of characters and their psychological space. Different characters in novel have their own space of individual including their residence and monologue. How much the space of individual could contain? In the New Year party, someone sang a western love song named "The Lass of Aughrim". Its mournful rhythm and grieved words brought about Gretta's sad memories of Fury. When Gretta and Gabriel walked towards the hotel in the heavy snow, Gabriel was excited with the help of alcohol, while Gretta was still lost in the memory of the past. Seeing his wife's gesture of walking, Gabriel had a train of thought. "She seemed to him so frail that he longed to defend her against something and then to be alone with her. Moments of their secret life together burst like stars upon his memory."(Joyce, 1996, p. 244) However, Gratta did not notice her husband's feeling. After returning the hotel space, Gabriel thought that it was wonderful to stay together in the hotel and have their individual space. They could escape from the dull lifestyle and social responsibility. He hoped that they could make good use of the chance to experience new life. But his wife responded little to his love. When Gabriel 
realized that Gretta's focus was not on him, he began to ask her the reason. His wife told him that Fury, a 17 years old boy, was her first love, who died for her in order to see her off when she left her grandmother's. His face, voice and the song were still in her deep heart although he died long time ago. If Gabriel could not control his space of society, it was necessary for him to control his space of individual. To his disappointment, Gretta's psychological space had been taken up by the dead-Fury. Although Fury was dead, he was still alive in Gretta's memory. By contrast, Gabriel was Gretta's husband, but he felt strongly that their love was dead. Time, here, had become a monster, swallowing people's hearts. People were not able to fight against time and treasure the past and the dead. Knowing the truth, Gabriel was angry resulting from his jealousy and fear. Gabriel was nervous when other talked about the west. So he refused Miss Ivors's invitation. The "west" appeared many times in the novel, especially in the description of Fury. Fury was born in the west and grew in the west. He sang the love song of west. Space of west belonged to the dead, symbolizing the traditional Irish culture and nationalism. That is why Gabriel did not want to go.

\section{Conclusion}

The Dead has no definite theme; it is characterized by a vague heterogeneity. Perhaps just because of this, it has been attracting more and more critics and readers to interpret it from many angles. As a matter of fact, Pythagorean Cosmology is the theory of mathematics and philosophy, which enables the analysis of space and music to be the focal issues in The Dead. Through concrete analysis of the meanings of music in The Dead, it is noteworthy that the music is the fruitful result of Joyce's extended meditation on art, Irish identity and loss. Vivid characters and profound themes unfold in a musical way. Music is closely linked with text and adds something new to the text, which has become the indispensable part of the novel and brought interest and beauty to the readers. Space of nature, space of society and space of individual are described respectively in The Dead. Meanwhile, space of nature is gifted with the color of culture and religion and shows spiritual specialty in Dublin. The alienation of thoughts in space of individual reflects a strange individual with self-doubt and soft psychological construction. To interpret The Dead from the perspective of space is a new way to relate the novel with society and culture.

It seems that the analysis of music and space in terms of Pythagorean Cosmology in this article may bring about different ideas from the literary elders. In fact, the article aims at opening a new door for literary criticism on James Joyce's novels. Just as the following paragraph says, "We must stop trying to discover the undiscoverable absolute truth and openly acknowledge that what may be right for one person may not be right for another. Acceptance, not criticism; open-mindedness not close-mindedness; tolerance, not bigotry; and love, not hatred most become the guiding principles of our lives. When we stop condemning ourselves and others for not having truth; then we can spend more time interpreting our lives and giving them meaning, as together we work and play." (Bressler, 1999, p. 119)

\section{References}

Booze, E. B. (1984). A Brief Introduction to Modern English Literature. Shanghai: Shanghai Foreign Education Press.

Bressler, C. E. (1999). Literary Criticism: An Introduction to Theory and Practice. Upper Saddle: Pentice-Hall, Inc.

Crang, M., \& Thrift, N. (2000). Thinking Space. London: Rootledge.

Heninger, S. K. Jr. (1974). Touches of Sweet Harmony: Pythagorean Cosmology and Renaissance Poetics. U.S.A.: Kingsport Press.

Joyce, J. (1996). Dubliners. London: Penguin Group.

Morris, B. (1973). James Joyce Dubliners and A Portrait Casebook Series. London: The Macmillan Press Ltd.

\section{Copyrights}

Copyright for this article is retained by the author(s), with first publication rights granted to the journal.

This is an open-access article distributed under the terms and conditions of the Creative Commons Attribution license (http://creativecommons.org/licenses/by/3.0/). 